\title{
Smoking cessation services in the Eastern Mediterranean Region: highlights and findings from the WHO Report on the Global Tobacco Epidemic 2019
}

Ahmad AlMulla, ${ }^{1}$ Norr Hassan-Yassoub, ${ }^{1}$ Dongbo Fu, ${ }^{2}$ Fatimah El-Awa, ${ }^{3}$ Raouf Alebshehy, ${ }^{4}$ Mahmoud Ismail ${ }^{3}$ and Charles P. Fraser ${ }^{3}$

${ }^{1}$ Tobacco Control Center, WHO Collaborative Center, Department of Medicine, Hamad Medical Corporation, Doha, Qatar. ${ }^{2}$ Tobacco Free Initiative, Prevention of Noncommunicable Diseases, World Health Organization, Geneva, Switzerland. ${ }^{3}$ Tobacco Free Initiative, Department Noncommunicable

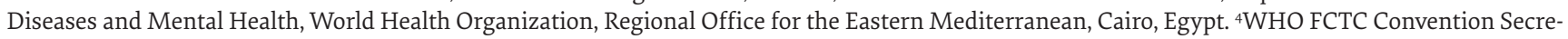
tariat, Geneva, Switzerland. (Correspondence to: Norr Hassan-Yassoub: nourhassanhmp@gmail.com)

\begin{abstract}
The report aimed to review and assess the status of tobacco cessation services in the Eastern Mediterranean Region (EMR). Nearly 70\% of people in the Region have legal access to nicotine-replacement therapy but for $77 \%$ of these people the costs of the treatment are not covered. Bupropion and Varenicline are legally available in 10 and 11 EMR countries respectively. Just under $50 \%$ of people in the Region have access to at least some cessation support in primary health care facilities. Around $32 \%$ of people have access to a national toll-free quit line. Costs for cessation services are fully covered in few EMR countries; however, cessation services in the Region must be improved. Member States should aim to increase the availability of, and financial support for, cessation treatments and support, which should be prioritized in primary health care facilities.
\end{abstract}

Keywords: smoking cessation; tobacco control; Eastern Mediterranean Region, substance use, addiction

Citation: Al-Mulla A; Hassan-Yassoub N; Fu D; El-Awa F; Alebshehy R; Ismail M; et al. East Mediterr Health J. 2020;26(1):110-115 https://doi.org/10.26719/2020.26.1.110

Received: 22/10/19; accepted: 15/12/19

Copyright (C) World Health Organization (WHO) 2020. Open Access. Some rights reserved. This work is available under the CC BY-NC-SA 3.0 IGO license (https://creativecommons.org/licenses/by-nc-sa/3.o/igo)

\section{Introduction}

Use of tobacco continues to be one of the major public health issues worldwide (1). According to the World Health Organization (WHO), tobacco kills almost half of its consumers, equivalent to nearly 7 million people annually (2). Without improvement, the number of tobacco-caused deaths will reach 8.3 million in 2030 (3). Nearly $80 \%$ of the 1.1 billion smokers globally live in low- and middle-income countries and it is in these countries that the burden of tobacco-related diseases and deaths is the heaviest (2). Supporting current smokers to quit smoking should be a key part of comprehensive tobacco control programmes and will contribute to reducing the burden of disease and improving population health (4). It is estimated that halving global adult consumption of tobacco by 2020 would avert around 180 million deaths by 2050 (5).

The WHO Eastern Mediterranean Region (EMR) consists of 22 high, middle and low-income countries/ territories (Afghanistan, Bahrain, Djibouti, Egypt, the Islamic Republic of Iran, Iraq, Jordan, Kuwait, Lebanon, Libya, Morocco, Oman, Pakistan, Palestine, Qatar, Saudi Arabia, Somalia, Sudan, Syrian Arab Republic, Tunisia, United Arab Emirates and Yemen). In this Region smoking prevalence is high, especially among males (36.8\%) (6-8). Globally smoking rates are falling and projected to continue to decline, but unlike all other WHO regions, smoking rates in the EMR are currently estimated to increase $(2,9)$. This calls for urgent action in the area of smoking cessation services.
Theimportance of cessation services to comprehensive tobacco control efforts is recognized in Article 14 of the WHO's Framework Convention on Tobacco Control (FCTC). WHO guidelines for this article recommend developing a comprehensive cessation support system to provide a range of services, including advice in primary care facilities, national toll-free quit lines, specialist cessation support and (free or low-cost) medication (10).

Presently, there has been no analysis of the smoking cessation services currently provided across EMR countries. To this end, this study examines and discusses the current status of smoking cessation support and treatment in the Region and provides recommendations for the way forward.

\section{Methods}

Data on cessation services in the countries collected for the WHO Report on the Global Tobacco Epidemic 2019 were used (11), primarily from official reports by WHO FCTC Parties to the Conference of Parties (COP) in 2018, and via a questionnaire sent to tobacco control focal points in the ministry of health of the country. Data published in the 2019 WHO Report were correct as of 31 December 2018. Data on the availability and cost of certain specific drugs (bupropion and varenicline), although not published in the 2019 WHO Report, were collected and recorded as part of the same mechanism.

Regional population coverage figures were calculated using the 2018 population figures from the Population Division of the United Nations Department of Economic 
and Social Affairs (the same source as the WHO Report on the Global Tobacco Epidemic 2019). Percentages were calculated by summing the populations of the relevant countries and considering the result as a percentage of the overall population of the Region.

\section{Results}

Nicotine replacement therapy treatments are legally available in just under two thirds of the countries of the Region (Afghanistan, Bahrain, Islamic Republic of Iran, Iraq, Jordan, Kuwait, Morocco, Oman, Pakistan, Palestine, Qatar, Saudi Arabia, Tunisia and United Arab Emirates). Given the population of the Region and the population size of these countries, this means that almost $70 \%$ of people have legal access to Nicotine replacement therapies. Furthermore, Nicotine replacement therapies can be bought in pharmacies without a prescription in 10 countries. In 3 countries (Morocco, Qatar and Tunisia) a prescription is needed. One country (Pakistan) did not provide information. Six countries include nicotine replacement therapies on their essential drug list. Of the countries where nicotine replacement therapy is available, costs are fully covered by national health insurance in 6 countries (Bahrain, Jordan, Kuwait, Qatar, Saudi Arabia and Tunisia), partially covered in Iraq and the United Arab Emirates, and not covered in the remaining 6 countries. Given population numbers, this means that for over $75 \%$ of the people who have legal access to nicotine replacement therapy in their country, this treatment is not cost-covered.

Bupropion and varenicline ${ }^{1}$ are legally sold in 10 and 11 countries respectively, but in very few countries are the costs for these drugs fully covered. The cost of bupropion is fully covered in Saudi Arabia and partially covered in Iraq and Qatar. For all countries in which bupropion is legally available and that provided information $(7$ countries), a prescription is required to buy the drug. The cost of varenicline is fully covered in Qatar and Saudi Arabia and partially covered in Jordan and the United Arab Emirates. Varenicline is available only with a prescription in 9 countries and without a prescription in the United Arab Emirates (1 country, the Islamic Republic of Iran, did not provide information).

Smoking cessation support is available in at least some (i.e., less than half of all) primary health care facilities in 16 countries. This means that just under $50 \%$ of people in the Region have, in principle, access to at least some cessation support via primary health care facilities in their country. In 4 countries (Morocco, Saudi Arabia, Syrian Arab Republic and Tunisia) this support is available in most (i.e., more than half of all) primary health care facilities. The cost for such support is at least partially covered in 12 of the 16 countries. Costs are fully covered in Bahrain, Jordan, Kuwait, Qatar and Saudi Arabia. Smoking cessation support is not available in any primary health care facility in Djibouti, Egypt, Oman,
Pakistan, Somalia and Yemen (amounting to just over half of the population of the Region).

Cessation support and treatment is available in at least some hospitals in 9 countries in the Region, and in 7 of these countries the costs are partially covered. Costs are only fully covered in Bahrain, Qatar and Saudi Arabia. Nine countries of the Region (Egypt, Islamic Republic of Iran, Jordan, Kuwait, Libya, Pakistan, Qatar, Saudi Arabia and the United Arab Emirates) also offer cessation support in dedicated tobacco cessation centres. All of these countries at least partially cover the costs for this support. In Kuwait, Saudi Arabia and the United Arab Emirates these costs are fully covered. Just over $32 \%$ of people in the Region have access to a national toll-free quit line (provided in Egypt, Islamic Republic of Iran, Kuwait, Saudi Arabia and the United Arab Emirates).

Most countries in the Region do not cover the full cost of cessation treatment and support. Cost coverage is best in primary health care facilities, for which 5 countries (Bahrain, Jordan, Kuwait, Qatar and Saudi Arabia) fully cover the cost of cessation treatment and support, and 7 further countries partially cover this cost. For hospitals and specialized cessation centres, less than half of the countries in the Region partially cover the costs of cessation support. Only 3 countries fully cover the cost of cessation support in these locations (hospitals: Bahrain, Qatar, Saudi Arabia; specialized cessation centres: Kuwait, Saudi Arabia, United Arab Emirates).

\section{Discussion}

Primary health care plays a pivotal role in initiating and maintaining smoking cessation efforts (12). As recognised by WHO (10), utilizing primary health care infrastructure in this way can allow widespread cessation systems to be rapidly introduced. In addition, counselling in such facilities by health workers other than physicians can allow the burden on the public health care system to be reduced (13). Despite these considerations, as described in the above analysis, a disappointingly small proportion of people in the Region live in countries where at least some primary health facilities offer cessation support. Very few countries provide such support in most facilities or fully cover the cost of the support. Unlike specialized cessation centres, which usually exist in only limited numbers, primary health care providers have the potential to reach a large proportion of a country's tobacco users with cessation support. This opportunity is largely being missed in the Region.

As recognized by WHO (10), nicotine replacement therapy should be made available to people in their countries as an evidence-based, effective medical aid for smoking cessation. Indeed, as recognized above, most people in the Region (70\%) live in countries where nicotine replacement therapy is legally available. The problem, however, is that for an even larger proportion of these

\footnotetext{
Bupropion is an antidepressant drug that reduces nicotine cravings and withdrawal symptoms. Varenicline reduces nicotine cravings and decreases the pleasurable effects of products containing nicotine.
} 
Table 1 Tobacco Cessation Interventions in the Eastern Mediterranean Region

\begin{tabular}{|c|c|c|c|c|}
\hline \multirow[t]{2}{*}{ Tobacco cessation interventions } & \multicolumn{2}{|c|}{$\begin{array}{l}\text { Number of countries with availability } \\
\text { of service }\end{array}$} & \multicolumn{2}{|c|}{$\begin{array}{l}\text { Number of countries where cost is } \\
\text { covered }\end{array}$} \\
\hline & $\begin{array}{l}\text { Majority } \\
\text { availability }\end{array}$ & Partial availability & Fully & Partially \\
\hline \multicolumn{5}{|l|}{ Tobacco Cessation Support } \\
\hline In primary care facilities & 4 & 12 & 5 & 7 \\
\hline In hospitals & 2 & 7 & 3 & 4 \\
\hline In specialized cessation centres & \multicolumn{2}{|c|}{9} & 3 & \\
\hline Nicotine replacement therapy & \multicolumn{2}{|c|}{14} & 6 & 2 \\
\hline Bupropion & \multicolumn{2}{|c|}{10} & 1 & 2 \\
\hline Varenicline & \multicolumn{2}{|c|}{11} & 2 & 2 \\
\hline National toll-free quit-line & \multicolumn{2}{|c|}{5} & \multicolumn{2}{|c|}{-} \\
\hline
\end{tabular}

people $(77 \%)$, the cost of nicotine replacement therapy is not covered at all via their national health insurance scheme. The resulting financial commitment to cessation products is especially detrimental for cessation efforts in lower-income countries. One reason for this discrepancy between legal availability and financial support may be that while many countries allow nicotine replacement therapies to be sold, far fewer include it on their essential drug list.

In addition, rates of access to non-nicotine-containing medication (i.e. bupropion and varenicline) are much lower than for nicotine replacement therapy. This is despite the fact that these drugs have been shown to improve cessation rates, especially when combined with behavioural support (14). In general, this lack of accessibility to both nicotine replacement therapy and other medication for cessation is unfortunate, especially given that quit rates can be increased by 3 to 6 times with medications (and appropriate behavioural support) (15).

Currently, less than a third of people in the Region have access to a toll-free quit line in their country. Such lines are an effective way for tobacco users who are ready to quit to easily access useful information and behavioural counselling (16) and they have the potential to reach up to $6 \%$ of all tobacco users per year (17). Those that use quit lines increase their absolute quit rate by 2 to 4 percentage points above quitting without assistance (18); this corresponds to a doubling in success rate (19). In addition, if the quit line is 'proactive' - for instance, counsellors make follow-up calls to the tobacco users who want to quit - then this rate can be increased further (20). A toll-free quit line is also relatively cheap to implement (11).

Few countries in the Region fully cover the cost of tobacco cessation support and medication. Disappointingly, this is even the case in primary health care facilities. Unsurprisingly, the countries that do fully cover the costs of these services and pharmacotherapies are almost exclusively the high-income Gulf Cooperation Council (GCC) countries, which have the financial resources to provide such support (21). Ideally, pharmacotherapy and counselling would be brought under national health insurance schemes to ensure widespread access and increase the proportion of smokers who attempt to quit, use tobacco cessation treatment and succeed in quitting (22).

\section{Challenges}

As more high-income nations tighten their tobacco regulations and increase their control efforts, the low and middle-income EMR countries - with their relatively relaxed tobacco control policies - may present a 'safe haven' for the tobacco industry (6). One significant challenge in this context is the lack of political commitment and resources in the Region to pursue substantive tobacco control reform. In the area of cessation support this is especially significant, given the need for significant financial commitment in providing the needed services. The problem is made worse by prolonged political instability in many countries in the Region.

Another challenge in increasing access to cessation services is simply a lack of the required infrastructure to enable such services to be implemented. Countries need to ensure widespread access to primary health care facilities before effective cessation support efforts can be implemented in such facilities. Increasing awareness among the population regarding the services that are available to them is also key in this regard.

Training and practices among health care workers pose a further challenge. Screening for, and recording, tobacco use is not a common practice among health care practitioners. Often they are not trained to monitor this use or provide other cessation support, including encouraging a quit attempt and referring to specialised tobacco dependence treatment centres $(23,24)$. In addition, research shows that tobacco control content in education centres for health professionals is inadequate (25). There is also a high prevalence of tobacco use among physicians and other health care workers (26-29), which undermines the central role that health care professionals should play in cessation support and in diminishing the social acceptability of tobacco use (10).

\section{Way forward}

The EMR is the only WHO region for which prevalence is not projected to decrease given current tobacco control 
efforts (9). This calls for quick and decisive action in all areas of tobacco control, including in providing cessation services to smokers. This report shows that while some effort is being made in this area, much more can and should be done. The following specific actions are recommended in light of the above analysis.

\section{Availability of treatments}

Countries should work to increase the availability, and decrease the cost, of evidenced-based cessation pharmacotherapies, including nicotine replacement therapy, bupropion and varenicline. This can be at least partly achieved by drug registration, direct import, collective bargaining and appropriate coordination with generic manufacturers (10).

\section{From legal availability to financial support}

The analysis shows that there is a large gap between the legal availability of a specific medication or means of support and this being financially accessible to the population. From the analysis, this is perhaps most evident for the accessibility of nicotine replacement therapy. Countries must be encouraged to move from simply allowing the sale of the various pharmacotherapies to committing to covering their cost, at least partially. While for many countries fully covering the costs of all medications will not be possible, through prioritization and partial coverage or subsidies, the accessibility of these treatments can be greatly increased (30).

\section{Quit lines}

More countries should (and certainly could) establish a national quit-line for cessation support. As the discussion noted, this is a cost-effective measure that does not require significant investment in infrastructure. For several countries in the Region, if they were to implement such a quit line they would be performing at the highest level for the WHO's cessation measure in the MPOWER package (11).

\section{Primary health care}

When investing in cessation support, countries should prioritize providing this support in primary health facilities, given their reach and presence in local communities. Surveillance in this area should also be increased as there are no significant studies on the number of smokers currently receiving cessation advice from primary health care facilities or on quitting rates after receiving such advice.

\section{Health care workers}

When introducing cessation schemes and projects, governments should ensure that health care workers receive the necessary training to effectively deliver the intended content and support to patients and current smokers (23). In addition, work should be done on discouraging smoking among this group. Policy change, backed by strong political commitment, is necessary to realise the benefit of tobacco control initiatives. This is particularly true in the low and middle-income countries of the Region, where cessation support, among other control measures, needs to be prioritized as an urgent public health intervention (31).

Funding: None.

Competing interests: None declared.

\section{Services de sevrage tabagique dans la Région de la Méditerranée orientale : faits marquants et conclusions issus du Rapport de l'OMS sur l'épidémie mondiale de tabagisme, 2019 \\ Résumé}

Le présent rapport a pour objectif d'examiner et d'évaluer l'état des services d'aide au sevrage tabagique dans la Région de la Méditerranée orientale. Près de $70 \%$ des habitants de cette Région bénéficient d'un accès légal aux traitements de substitution nicotinique (TSN), mais pour $77 \%$ d'entre eux, les coûts de ces traitements ne sont pas pris en charge. Le bupropion et la varénicline sont légalement disponibles dans 10 et 11 pays de la Région de la Méditerranée orientale, respectivement. Un peu moins de $50 \%$ de la population de la Région a accès à au moins une forme d'aide au sevrage tabagique assurée par les établissements de soins de santé primaires. Près de $32 \%$ des habitants ont accès à un service téléphonique d'aide au sevrage tabagique national et gratuit. Les coûts des services d'aide au sevrage tabagique sont entièrement pris en charge dans un nombre restreint de pays de la Région ; ces services doivent cependant être améliorés. Les États Membres devraient se fixer pour objectif d'accroître le soutien financier et d'améliorer la mise à disposition de traitements et d'une aide pour le sevrage tabagique, qui devraient constituer une priorité dans les établissements de soins de santé primaires. 


$$
\begin{aligned}
& \text { خدمات الإقلاع عن التدخين في إقليم شرق المتوسط: أبرز التطورات والنتائج من تقرير منظمة الصحة العالمية بشأن وباء التبخ العالمي } \\
& \text { لعام } 19 \\
& \text { أحمد الملا، نور حسن-يعسوب، دونجبو فو، فاطمة العوا، رعوف الابشيهى، محمود إسلاعيل، تشالرز فريزر } \\
& \text { الخالاصة }
\end{aligned}
$$

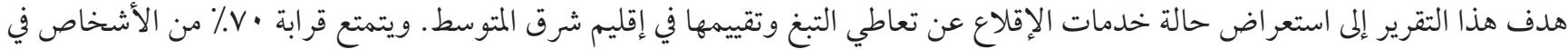

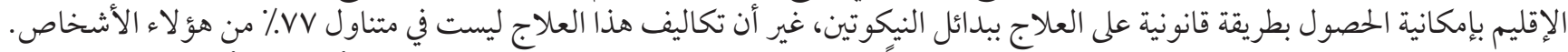

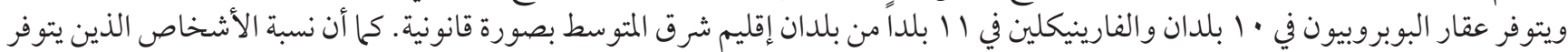

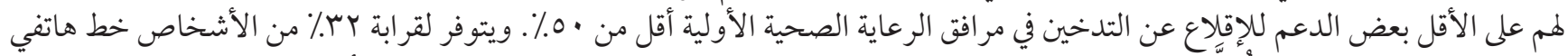

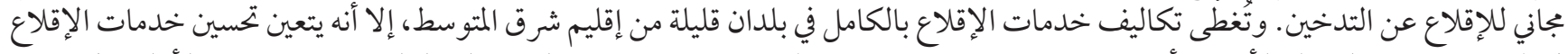

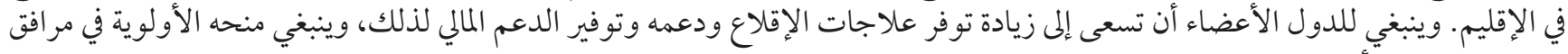
الرعاية الصحية الأولية.

\section{References}

1. Heydari G, Talischi F, Mojgani N, Masjedi MR, Algouhmani H, Lando HA, et al. Status and costs of smoking cessation in countries of the Eastern Mediterranean Region. East Mediterr Health J. 2012;18(11):1102-1106

2. World Health Organization. Prevalence of tobacco smoking, Global Health Observatory data. Geneva: World Health Organization; 2018. (https://www.who.int/gho/tobacco/use/en/, accessed 1 September 2019).

3. Mathers CD, Loncar D. Projections of global mortality and burden of disease from 2002 to 2030. PLoS Medicine. 2006;3(11):e442

4. Peto R, Lopez AD. The future worldwide health effects of current smoking patterns. In Tobacco and public health: Science and policy. Oxford: Oxford University Press; 2004:281-286

5. Jamison DT, Breman JG, Measham AR, Alleyne G, Claeson M, Evans DB, et al. Disease control priorities in developing countries. Washington, DC: The World Bank; 2006.

6. Heydari G, Zaatari G, Al-Lawati JA, El-Awa F, Fouad H. MPOWER, needs and challenges: trends in the implementation of the WHO FCTC in the Eastern Mediterranean Region. East Mediterr Health J. 2018;24(1):63-71

7. Al-Mulla AM, Abdou Helmy S, Al-Lawati JA, Al Nasser S, S. Abdel Rahman A, Almutawa A, et al. Prevalence of tobacco use among students aged 13-15 years in Health Ministers' Council/Gulf Cooperation Council Member States, 2001-2004. J School Health. 2008;78(6):337-343

8. World Health Organization. WHO Report on the Global Tobacco Epidemic. Geneva: World Health Organization; 2015.

9. World Health Organization. WHO Global Report on Trends in the Prevalence of Smoking 2000-2025 (2nd Edition). Geneva: World Health Organization; 2018.

10. World Health Organization. Guidelines for the implementation of Article 14 of the FCTC. Geneva: World Health Organization; 2010 (https://www.who.int/fctc/guidelines/adopted/article_14/en/, accessed 29 August 2019).

11. World Health Organization. WHO Report on the Global Tobacco Epidemic 2019. Geneva: World Health Organization; 2019.

12. Aveyard P, Begh PR, Parsons A, West R. Brief opportunistic smoking cessation interventions: a systematic review and meta-analysis to compare advice to quit and offer assistance. Addiction. 2012;107(6):1066-1073

13. McIvor A, Assaad J, Brosky JM, Demarest G, Desmarais P, Weinberg R. Best practices for smoking cessation interventions in primary care. Can Respir J. 2009;16(4):129-134

14. Ebbert JO, Croghan IT, Sood A, Schroeder DR, Hays JT, Hurt RD. Varenicline and bupropion sustained-release combination therapy for smoking cessation. Nicotine Tob Res. 2009;11(3):234-239

15. World Health Organization. The WHO Report on the Global Tobacco Epidemic. Geneva: World Health Organization; 2008 (https://www.who.int/tobacco/mpower/mpower_report_full_2008.pdf, accessed 29 August 2019).

16. Lichtenstein E, Zhu SH, Tedeschi GJ. Smoking cessation quit-lines: an under-recognized intervention success story. Amer Psychologist. 2010;65(4):252

17. World Health Organization. Developing and improving national toll-free tobacco quit line services: A manual. Geneva: World Health Organization; 2011.

18. Stead LF, Hartmann-Boyce J, Perera R, Lancaster T. Telephone counselling for smoking cessation. Cochrane Database Syst Rev. 2013;12(8):CDoo1188

19. Hollis JF, McAfee TA, Fellows JL, Zbikowski SM, Stark M, Riedlinger K. The effectiveness and cost-effectiveness of telephone counselling and the nicotine patch in a state tobacco quitline. Tob Control. 2007;16(Suppl 1):53-59

20. Stead LF, Hartmann-Boyce J, Perera R, Lancaster T. Telephone counselling for smoking cessation. Cochrane Database Syst Rev. 2013(8):CDoo2850 
21. Awan KH, Hussain QA, Khan S, Peeran SW, Hamam MK, Hadlaq EA, et al. Accomplishments and challenges in tobacco control endeavours: Report from the Gulf Cooperation Council Countries. Saudi Dent J. 2017:30(1):13-18

22. van den Brand FA, Nagelhout A, Reda GE, Winkens AA, Evers SM, Kotz D et al. Healthcare financing systems for increasing the use of tobacco dependence treatment. Cochrane Database Syst Rev. 2017;9:CDoo4305

23. Hawari FI, Bader RK. Advancing tobacco dependence treatment services in the Eastern Mediterranean Region: International collaboration for training and capacity-building. Sultan Qaboos Univ Med J. 2014;14(4):e442

24. World Health Organization. WHO Framework Convention on Tobacco Control: Guidelines for Implementation of Article 5.3 and Articles 8 to 14. Geneva: World Health Organization; 2013.

25. World Health Organisation. The role of health professionals in tobacco control. Geneva: World Health Organization; 2005.

26. Mahdi HA, Elmorsy SA, Melebari LA, Al-Masudi SM, Sharbini DA, Naijar AG, et al. Prevalence and intensity of smoking among healthcare workers and their attitude and behaviour towards smoking cessation in the western region of Saudi Arabia: A cross-sectional study. Tob Prev Cessation. 2018;4:30

27. Mansoura FI, Abdulmalik MA, Salama RE. Profile of smoking among primary healthcare doctors in Doha, Qatar, 2007. Qatar Med J. 2010;2 https://doi.org/10.5339/qmj.2010.2.14

28. Smith DR, Leggat PA. An international review of tobacco smoking in the medical profession 197-2004. BMC Public Health. 2007;7(1):115

29. Abdulateef DS, Ali AJ, Mohesh MG, Abdulateef DS. Smoking knowledge, attitude and practics among healthcare professionals from Sulaymaniyah City/Iraq. Tob Use Insights. 2016;9:1-6

30. Murthy P, Saddichha S. Tobacco cessation services in India: Recent developments and the need for expansion. India J Cancer. 2010;47(5):69

31. Abdullah ASM, Husten CG. Promotion of smoking cessation in developing countries: a framework for urgent public health interventions. Thorax. 2004;59(7):623-630 